\title{
Seismic behaviour analysis and retrofitting of a row building
}

CHAPTER · SEPTEMBER 2015

DOI: $10.1201 / \mathrm{b} 18856-45$

READS

81

6 AUTHORS, INCLUDING:

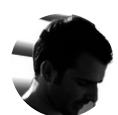

Alexandre A. Costa

Instituto Superior de Engenharia do Porto

54 PUBLICATIONS 159 CITATIONS

SEE PROFILE

Hugo Rodrigues

Instituto Politécnico de Leiria

131 PUBLICATIONS 376 CITATIONS

SEE PROFILE

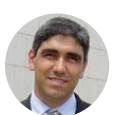

H. Varum

University of Porto

413 PUBLICATIONS 1,012 CITATIONS

SEE PROFILE

Graça Vasconcelos

University of Minho

104 PUBLICATIONS 349 CITATIONS

SEE PROFILE 


\title{
Seismic behavior analysis and retrofitting of a row building
}

\author{
R. S. Barros \& A. Costa \\ RISCO - Department of Civil Engineering, University of Aveiro, Portugal \\ H. Varum \\ CONSTRUCT-LESE, Department of Civil Engineering, Faculty of Engineering, University of Porto, Portugal \\ H. Rodrigues \\ RISCO - School of Technology and Management, Polytechnic Institute of Leiria, Portugal
}

P.B. Lourenço \& G. Vasconcelos

ISISE, Department of Civil Engineering, University of Minho, Guimarães, Portugal

\begin{abstract}
Rammed earth is one of the oldest building materials in the world and is present in Portugal with a particular focus in the South of the country. The mechanical properties and the structural behavior of rammed earth constructions have been the subject of study of many researchers in the recent years. This study is part of a broader research on vernacular seismic culture in Portugal. Numerical analyzes were carried out to assess the influence of different retrofitting solutions in the behavior and seismic performance of an rammed earth building representative of the vernacular heritage of Alentejo region. Understating the structural fragilities of this type of constructions allowed determining the most appropriate retrofitting solutions.
\end{abstract}

\section{INTRODUCTION}

Vernacular constructions exist all around the world. Many of these constructions, besides their cultural and architectural heritage value, in many cases, present a pronounced level of degradation, urging for the need of conservation and strengthening actions.

Portugal may suffer with moderate seismic events, as evidenced in historical past events. The past seismic activity, particularly in the south of the country, have drove the implementation of some retrofitting measures in the built vernacular heritage, including the insertion of strengthening elements like ties, reinforcing rings, buttresses and other reinforcement elements. The insertion of these elements contribute to enhance the connection between structural elements, and to the improvement of the structural behaviour and performance of the buildings.

This chapter presents the main results of a numerical study of the influence and effectiveness of common seismic improvement measures typically found in vernacular constructions.

In this study, it was selected a building representative of the vernacular architecture in certain localities in the South of Portugal. The building model was calibrated with information on material properties and structural characteristics and, with the calibrated model, parametric analyses are performed to assess the influence of different retrofitting solutions in their behavior and seismic performance.
The analysis of the numerical results gives a first insight on the behaviour of these type of vernacular constructions, and point out which retrofitting solutions may be more efficient in their seismic performance enhancement. The numerical results may also contribute for a better understating of the structural fragilities of these constructions, namely in temrs of demands distribution in the structural elements and structural damage distribution, for seimic demands. (Vicente et al., 2011)

\section{DESCRIPTION OF THE CASE STUDY}

For the selection of the building studied were taken into account the objectives of the numerical study developed under the SEISMIC-V project. The case study is located in Alcácer do Sal, district of Setúbal, in Portugal. It is a building with eight spaces and the vertical structural elements are principally rammed earth walls, with some elements in stone/brick masonry. The walls are $3.0 \mathrm{~m}$ high in average and have a thickness of $0.50 \mathrm{~m}$. The building has a regular plan (see Figures 1 and 2). The roof is gabled and possesses a wooden structure coated with ceramic tiles (Correia, 2007). 


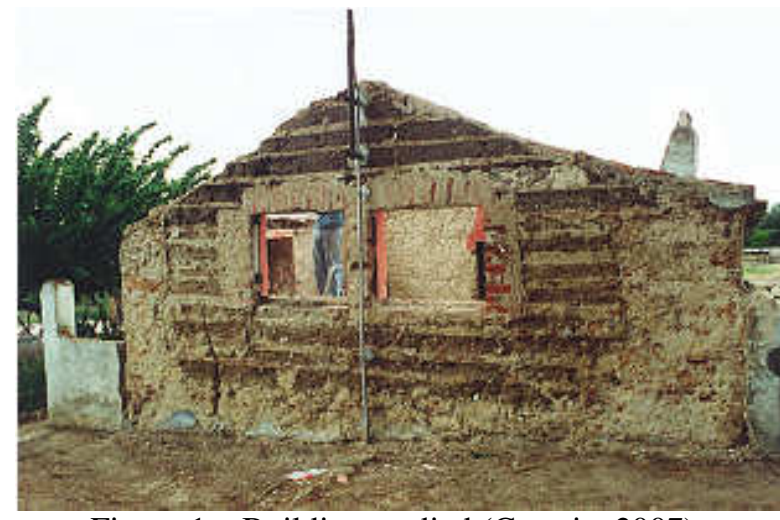

Figure 1 - Building studied (Correia, 2007).

Figure 2 - Plan and elevation (Correia, 2007).

\section{FINITE ELEMENT MODEL AND STRENGTHENING SOLUTIONS}

To understand the structural behaviour of this traditional building typology, the selected building was modelled with a finite element tool. The results of the analyses with the numerical models will help in the vulnerability evaluation, on the identification of fragile parts of these buildings, and in the efficiency assessment of different retrofitting measures.

Numerical analyses were performed in the finite element program MIDAS FEA. The simplified model was developed based on the available information on the selected building case study. The building model is symmetric in one direction, and has an irregular geometry in plan defined by four interior partition walls, as represented in Figure 3. The walls have $3.0 \mathrm{~m}$ height and $0.5 \mathrm{~m}$ of thickness, as indicated in the case study presented in the previous section.

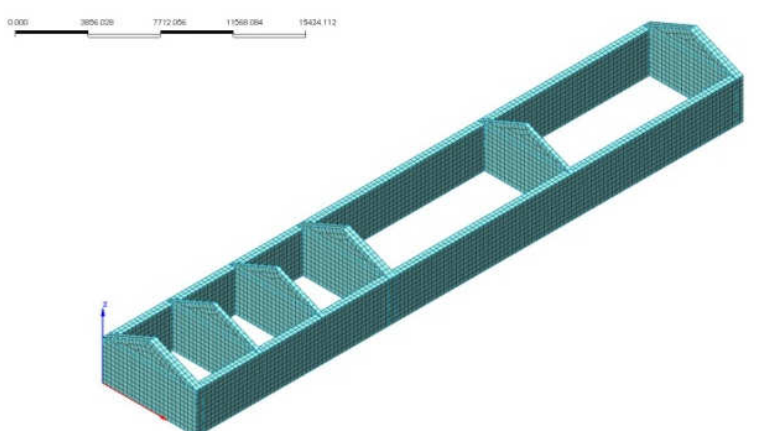

Figure 3 - Model developed in MIDAS FEA software.

In the model, all walls were considered as made of rammed earth. To define the material properties, it was made a literature survey to obtain reference values (see Table 1). Based on the survey, the properties of the rammed earth adopted in the numerical models developed in this study are presented in Table 2 .

Table 1 - Values adopted by other authors (credits: RISCO).

\begin{tabular}{lcccc}
\hline Reference & $\mathrm{E}(\mathrm{MPa})$ & $\mathrm{f}_{\mathrm{t}}(\mathrm{MPa})$ & $\mathrm{f}_{\mathrm{c}}(\mathrm{MPa})$ & $\mathrm{v}$ \\
\hline $\begin{array}{l}\text { Limón et al. } \\
(1998)^{*}\end{array}$ & 922 & 0.29 & 2.45 & 0.30 \\
$\begin{array}{l}\text { Gomes et al. } \\
(2011)^{*}\end{array}$ & 200 & 0.13 & 0.67 & 0.35 \\
$\begin{array}{l}\text { Silva (2013)* } \\
\text { Gallego and }\end{array}$ & 300 & 0.10 & 1.00 & 0.30 \\
$\begin{array}{l}\text { Arto (2015)* } \\
\text { Miccoli et al. }\end{array}$ & 250 & 0.29 & 2.00 & --- \\
$\begin{array}{l}\text { (2014) } \\
\text { * Obtained experimental values }\end{array}$ & 4207 & 0.37 & 3.70 & 0.27 \\
\hline
\end{tabular}

Table 2 - Adopted values for the mechanical properties of the rammed earth in the numerical model (credits: RISCO).

\begin{tabular}{cccc}
\hline $\mathrm{E}(\mathrm{MPa})$ & $\mathrm{f}_{\mathrm{t}}(\mathrm{MPa})$ & $\mathrm{f}_{\mathrm{c}}(\mathrm{MPa})$ & $\mathrm{v}$ \\
\hline 300 & 0.05 & 1.0 & 0.1 \\
\hline
\end{tabular}

For the finite element model, it was considered solid elements and a mesh with elements dimensions of $300 \mathrm{~mm}$ approximately, having the walls two solid elements in their thickness (see Figure 3). As boundary conditions were restricted the horizontal translational displacements of all nodes at the base of the model, simulating the foundations. In the model was not considered the roof structure, due to its weakness, but their weight was simulated with an equivalent distributed load of $0.001 \mathrm{~N} / \mathrm{mm}^{2}$ (benchmark for roofs with wooden structure and ceramic tiles as cover - Reis et al., 2005) applied on the top of the walls.

The demands are applied in two phases, first the vertical dead load, and then the lateral demand simulating the seismic loading. The seismic loading is imposed as an equivalent horizontal distributed load, proportional to the element mass, for increasing seismic levels $(0.2 \mathrm{~g}$ to $1.0 \mathrm{~g})$, applied in two independent directions ( $\mathrm{X}$ and $\mathrm{Y}$ ). 
To simulate the rammed earth walls, the total strain crack model was adopted in the non-linear analyses. For the material behavior in tension was considered the Hordijk function (Figure 4a), and the parabolic law for compression (Figure 4b).
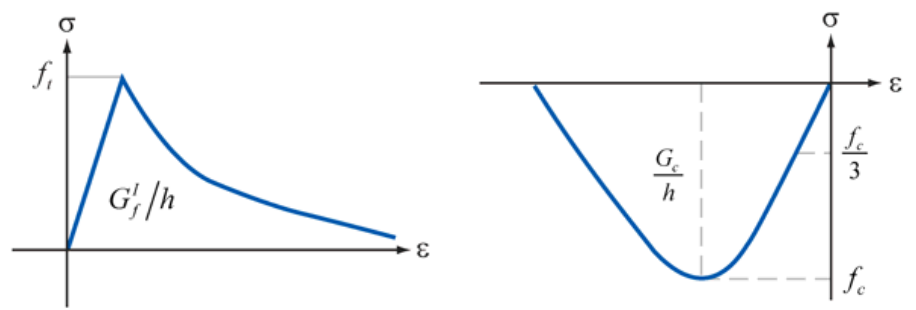

Figure 4 - Behaviour laws for the rammed earth: a) Hordijk function in tension; b) Parabolic function in compression (credits: MIDAS FEA).

It was intended to analyze the influence of the most common strengthening measures applied in the typical vernacular buildings of Alentejo region. Therefore, three seismic reinforcement strategies were studied (see Figure 5), two different configurations of buttresses distribution and one solution based on the use of tie rods. For the buttresses, idealized with a composition similar to the rammed earth walls, the same material properties were considered in the numerical analyses.

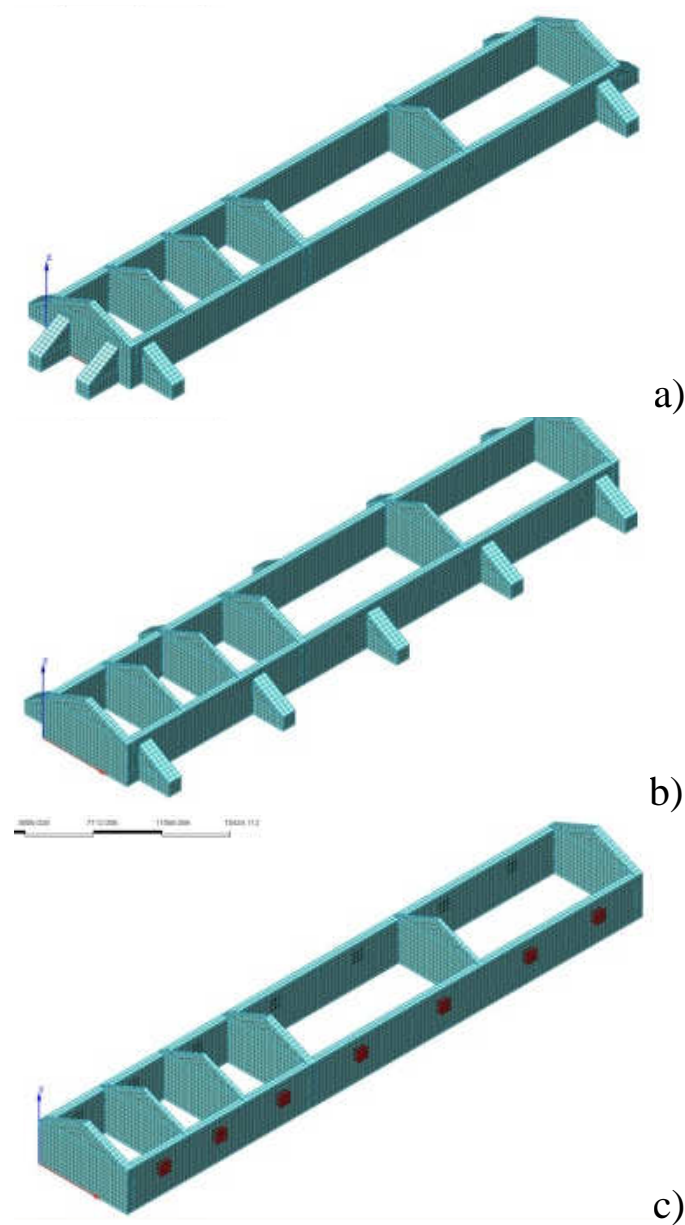

Figure 5 - Reinforcement solutions studied: a) Buttresses only at building corners (B); b) Buttresses along the longer walls (BLW); c) Rods (R) (credits: RISCO).
The strengthening with buttresses only at the building corners (B), shown in Figure 5a), is the most common solution in the rammed earth constructions of the south of Portugal. It was also studied a distribution of buttresses along the long walls (BLW) and a retrofitting solution based on the use of tie rods $(\mathrm{R})$ perpendicular to the long walls, to improve the structural behavior. With the latter retrofitting solutions, it is intended to reduce the potential of development of out-of-plane mechanism of the longer walls.

\section{RESULTS AND ANALYSIS}

The results obtained with the numerical models are presented and discussed in three phases. Firstly, are analyzed the results for the static vertical loads and the first natural mode is discussed. Then, is analyzed the response of the structure for increasing seismic demands in each direction. Finally, are presented the results of the seismic vulnerability reduction with the retrofitting solutions studied.

From the analysis of the results obtained with the non-linear model for the vertical static loads it was observed, as expected, that the maximum vertical strain reaches reduced values (approximately $0.115 \mathrm{MPa}$, see Figure 6a). From the modal analysis, it was observed that the first mode presents dominantly transversal displacements of the long external walls, highlighting the potential for the development of out-of-plane mechanisms of the façade walls (see Figure 6b).
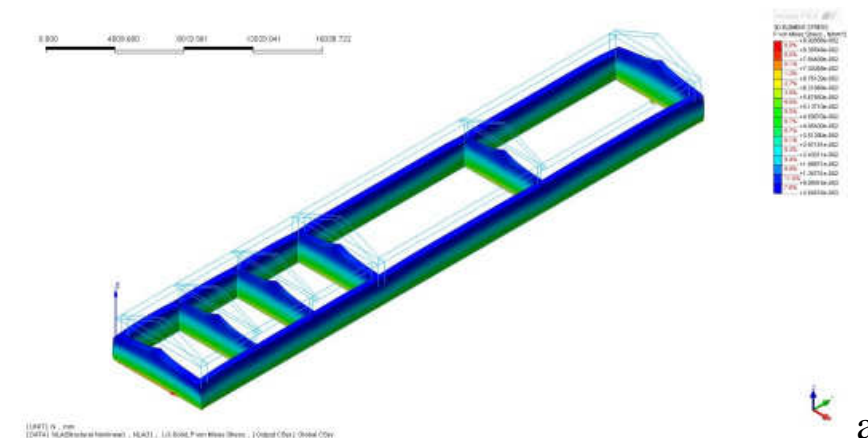

a)
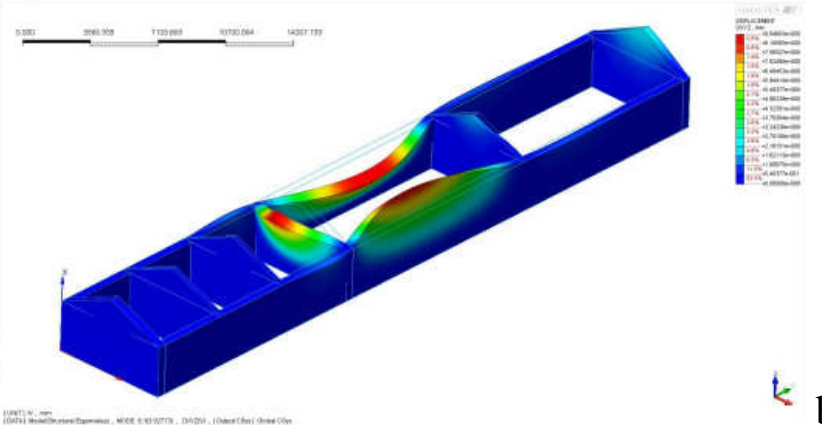

Figure 6 - Results: a) response for the vertical loads; b) 1st mode of the structure (credits: RISCO).

From the analysis of the results corresponding to an equivalent horizontal seismic demand of $1 \mathrm{~g}$ imposed in the $\mathrm{X}$ direction, it is observed a maximum 
displacement in this direction of $73.1 \mathrm{~mm}$ (Figure 7). The maximum strain and damage develops at the base of the walls perpendicular to the direction of the applied force, as well as in the connection between walls.

When imposing the horizontal load $(1 \mathrm{~g})$ in the $\mathrm{Y}$ direction, a maximum displacement in this direction of $304.3 \mathrm{~mm}$ is reached. For the seismic demand in Y direction, the maximum strain and damages develops also in the base of the walls perpendicular to the direction of the applied force, and also in corners and in the regions of connection between walls.
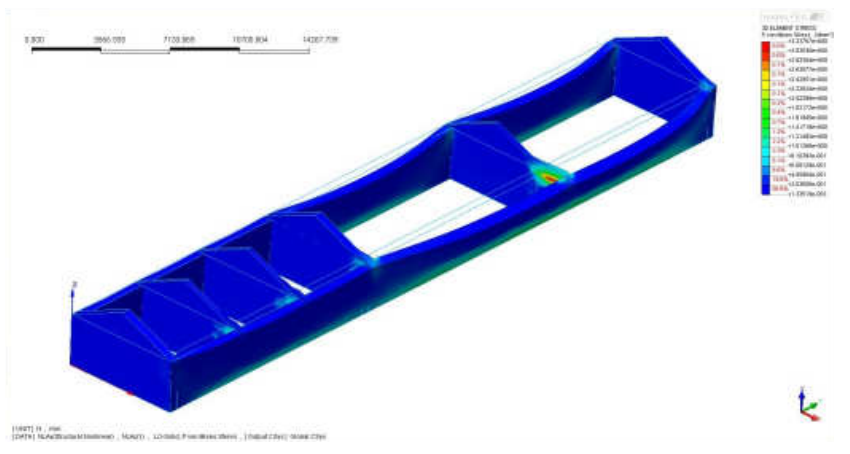

Figure 7 - Response in terms of maximum strain distribution for the seismic demand ( $1 \mathrm{~g})$ in $\mathrm{X}$ direction.

The damage evolution is presented in Figures 8 and 9, for increasing seismic demands in the $X$ and $\mathrm{Y}$ direction, respectively. For the seismic demands in the $\mathrm{X}$ direction, the damage start in the base and central areas of the longitudinal walls. Then, the damage evolves towards the perpendicular walls, until the collapse of the region connecting perpendicular walls (Figure 8 and Figure 9). For the demands in the $\mathrm{Y}$ direction, it was observed that damage start in the connection between the inner and outer walls. With the increasing of the seismic demand, the damages develop towards the interior walls until the collapse of the walls perpendicular to the seismic loading imposed (Figure 10 and Figure 11).

$0.2 \mathrm{~g}$

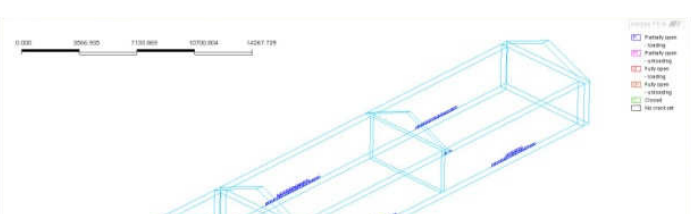

$0.4 \mathrm{~g}$

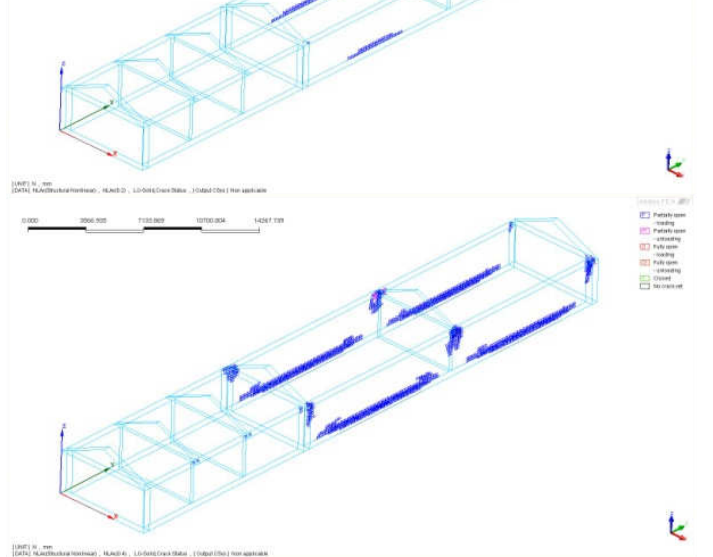

Figure 8 - Damage distribution evolution for seismic demands in X direction (credits: RISCO).

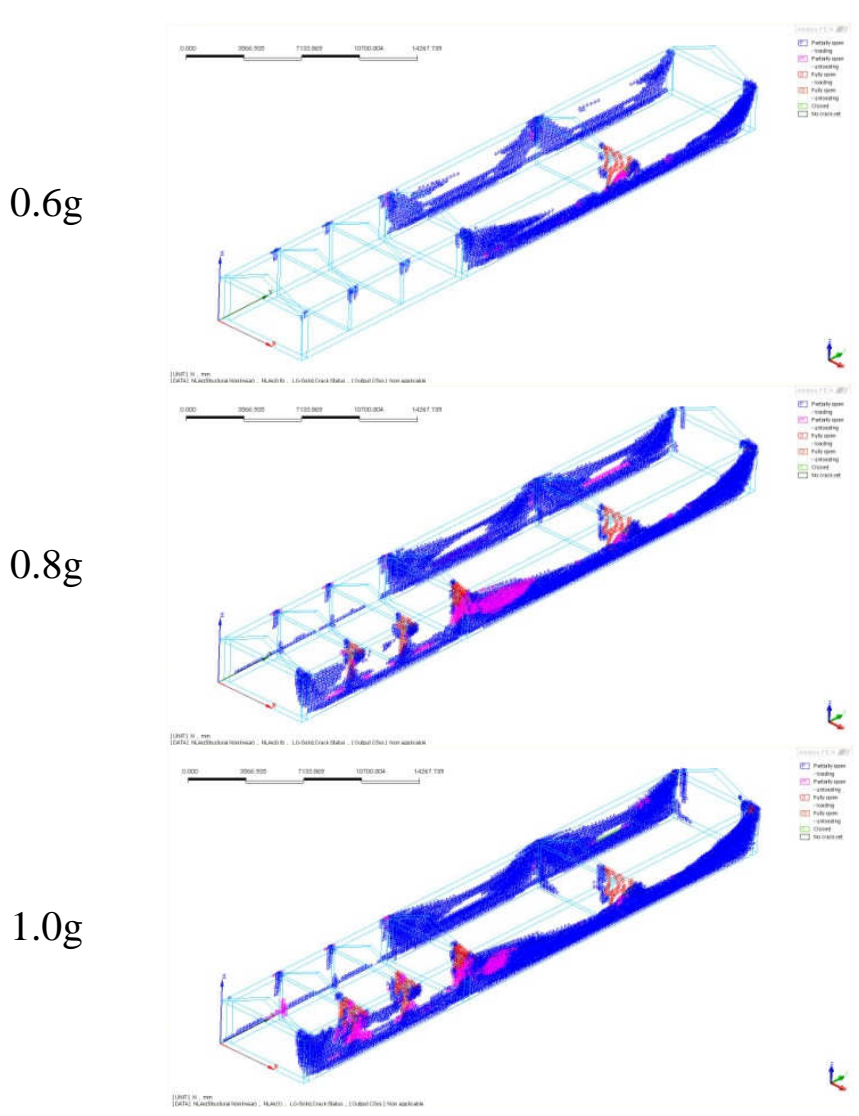

Figure 9 - Damage distribution evolution for seismic demands in X direction (credits: RISCO).

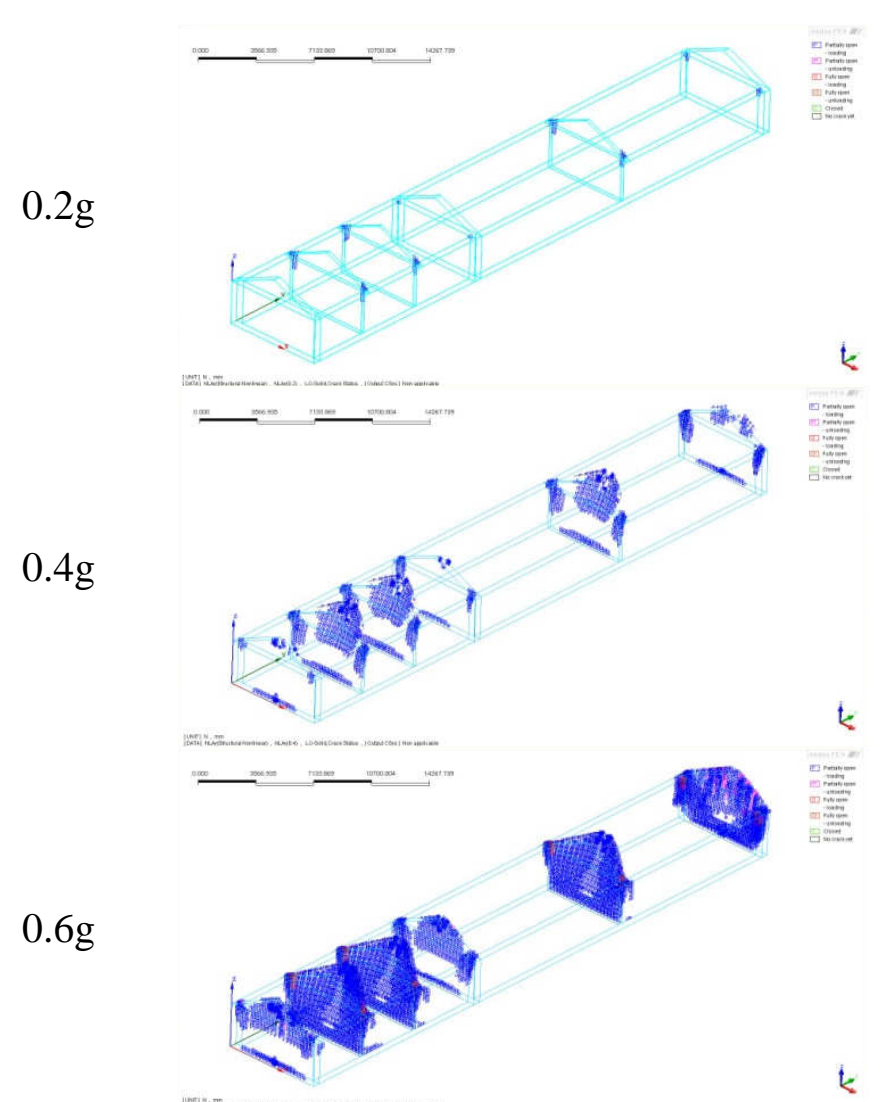

Figure $10-$ Damage distribution evolution for seismic demands in Y direction (credits: RISCO). 
$0.8 \mathrm{~g}$
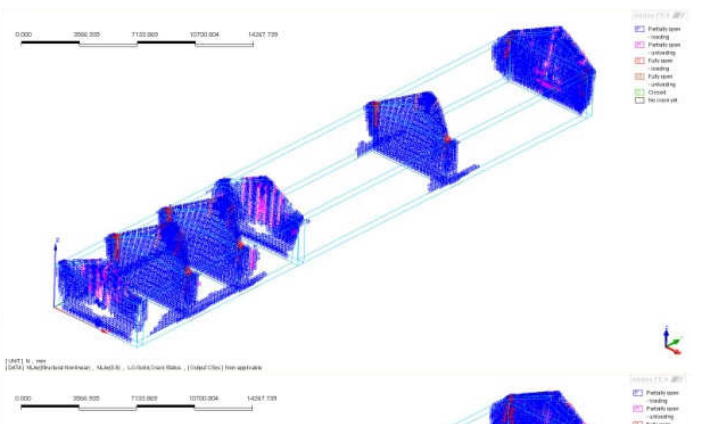

$1.0 \mathrm{~g}$
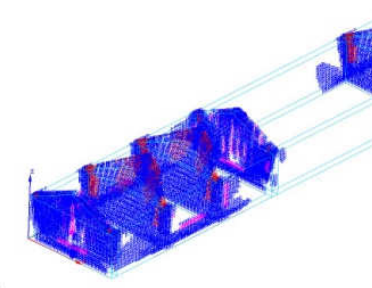

k

k

Figure 11 - Damage distribution evolution for seismic demands in Y direction (credits: RISCO).

Based on this prior analyses, it is clear that for the building studied, the out-of-plane collapse mechanism of the longer walls is one of the major vulnerabilities of the studied buildings. Thus, the strengthening solutions studied, and presented next, correspond to the scenario of the seismic action in the Y direction.
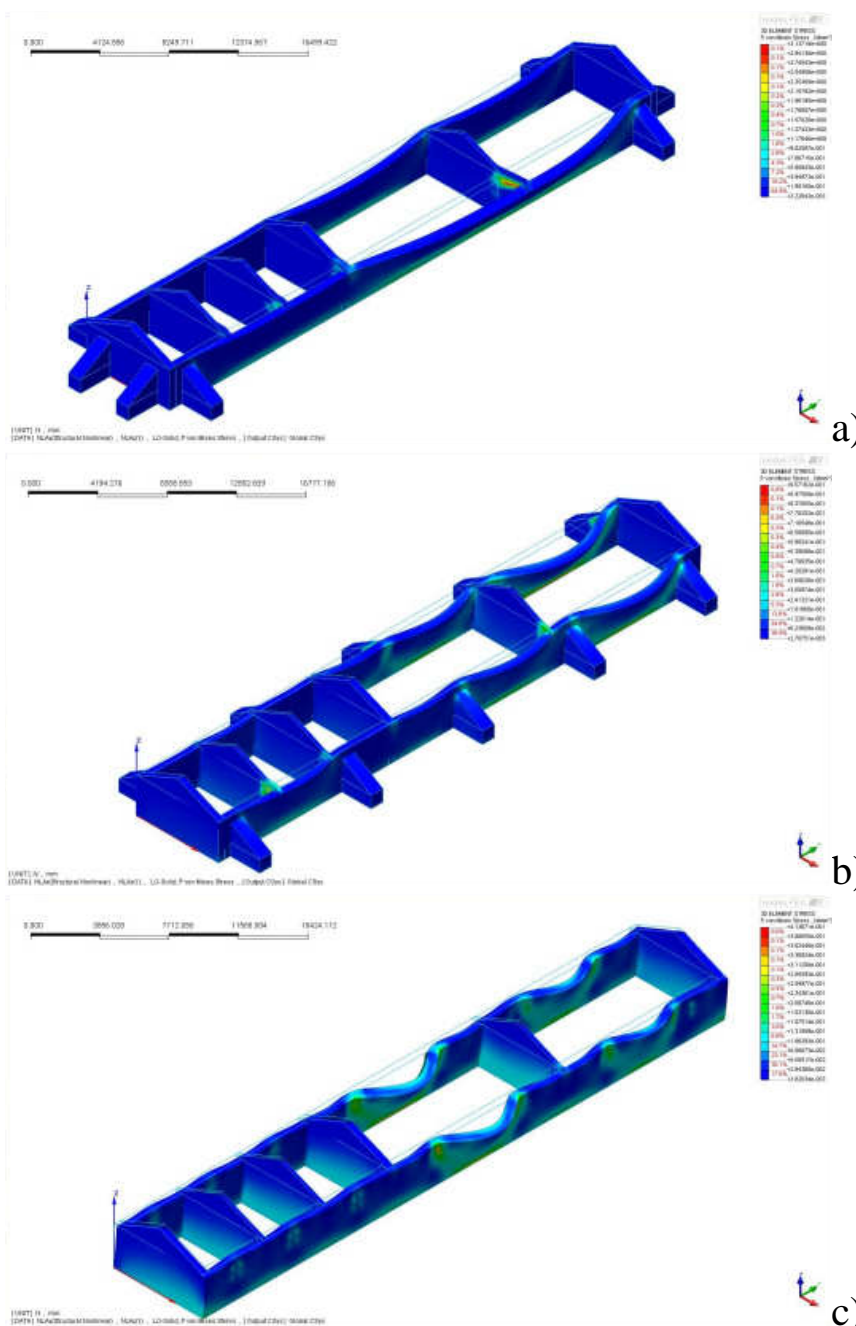

b)

Figure 12 - Maximum stress distribution and deformed shape for accelerations of $1 \mathrm{~g}$, for the models simulating the retrofitting solutions: a) B; b) BLW; c) R (credits: RISCO).
With the implementation of buttresses (B), for the horizontal seismic demand in $\mathrm{Y}$ direction, an increase in the maximum displacement in this direction is observed. In fact, the local stiffening of the building corners with buttresses, deformation demands tend to concentrate in the walls in the central part of the building. This retrofitting solution leads to a maximum displacement of $90.6 \mathrm{~mm}$, while for the non-retrofitted model a maximum displacement of $73.1 \mathrm{~mm}$ was observed, for $1 \mathrm{~g}$ seismic demand.

With the solution corresponding to the use of buttresses in the longest walls (BLW), the out-of-plane displacements decreases to $21.1 \mathrm{~mm}$, and the displacement in these points is reduced to $7.3 \mathrm{~mm}$ in the model simulating the retrofitting with ties $(\mathrm{R})$.

In terms of maximum stress, for the $\mathrm{B}$ model a maximum stress of $13.7 \mathrm{MPa}$ is observed, while for the BLW model the maximum stress decreases to $1.5 \mathrm{MPa}$, and for the $\mathrm{R}$ model to $0.4 \mathrm{MPa}$.

In Figure 13 and Figure 14 are presented the curves with the evolution of horizontal displacement with the seismic demand, for three critical points, at the top of the walls, representative of the building response, that allow comparing the efficiency of the studied retrofitting solutions. Analyzing the response of the walls' midpoint, it is observed that the BLW and $\mathrm{R}$ solutions improves largely the performance of these walls. At the building corners, all the reinforcement solutions improved the behavior, either for the seismic demand in $\mathrm{X}$ and $\mathrm{Y}$ direction.
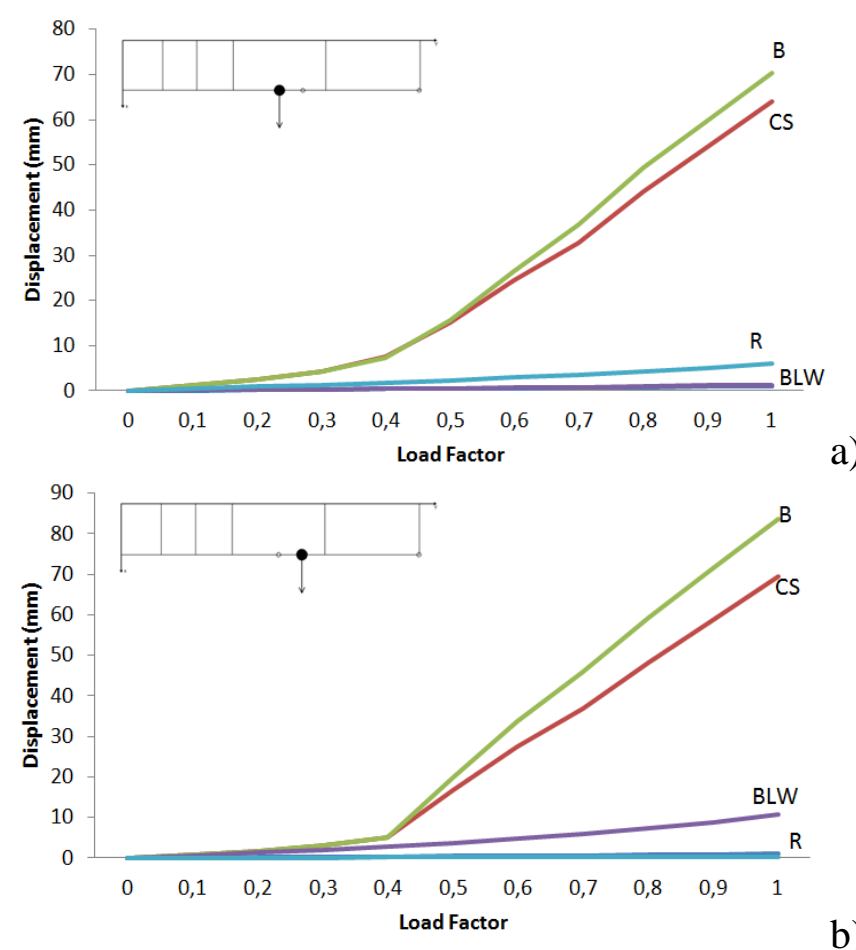

b)

Figure 13 - Evolutions of the horizontal displacement for increasing seismic load; a) Central point; b) Middle point (credits: RISCO). 


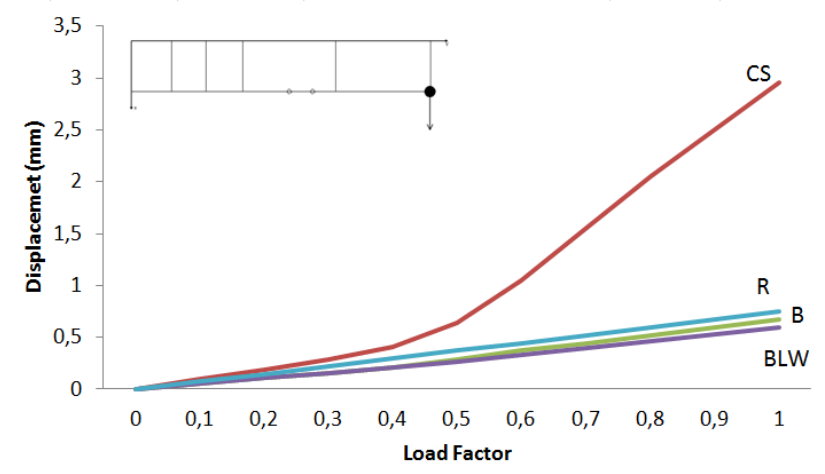

a)

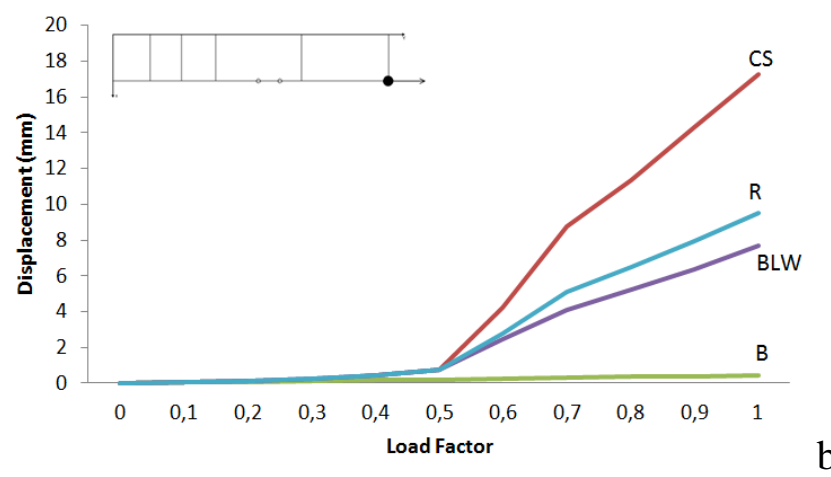

b)

Figure 14 - Evolutions of the horizontal displacement for increasing seismic load; a) Corner X direction; b) Corner Y direction (credits: RISCO).

In Figure 15 are presented the damage distributions for two levels of seismic demand, for the three retrofitting solutions studied. Model $\mathrm{R}$ represent the solution that more reduces the damage up to an equivalent seismic demand of $0.6 \mathrm{~g}$. A retrofitting solution commonly adopted in the rammed earth constructions in the south of Portugal was the installation of buttresses (model B).

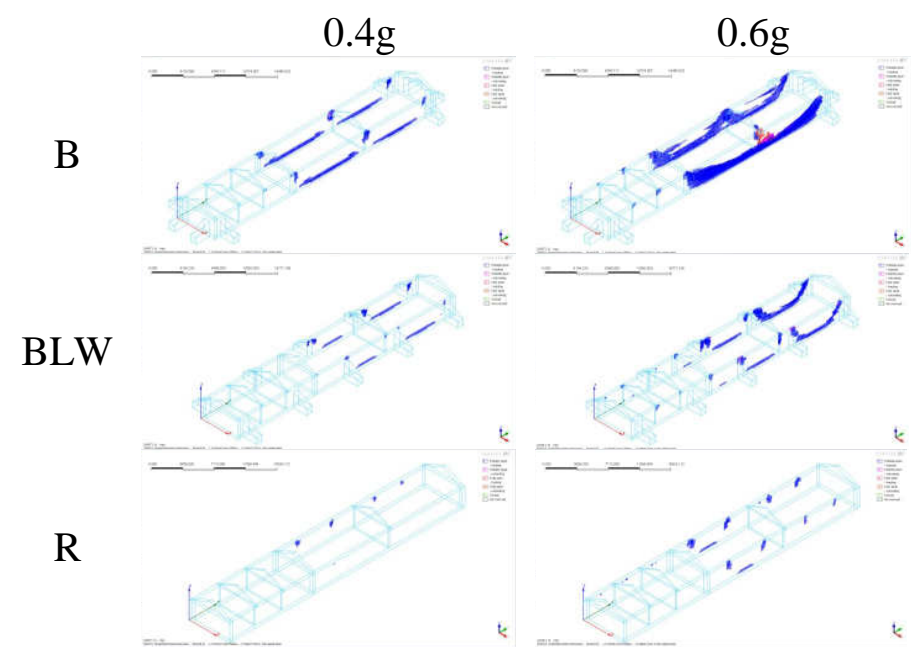

Figure 15 - Damage distribution (credits: RISCO).

\section{FINAL COMMENTS}

The south of Portugal, and in particular the Alentejo region, is a region with potential moderate seismic activity. Through the results obtained in this study, it was possible to observe that the rammed earth vernacular existing constructions commonly found in the south of Portugal can suffer substantial damages when subjected to earthquakes with accelerations up to $0.4 \mathrm{~g}$. For seismic demand with larger peak accelerations, the collapse of principal structural elements may occurs, especially associated to outof-plane collapses of the outer walls.

A common strengthening solution founded in vernacular constructions in the South of Portugal, the use of buttresses in the building corners, may not reduce significantly the seismic vulnerability of these buildings. In fact, for buildings with long walls, the out-of-plane mechanism may control their seismic performance.

In these buildings, the adoption of buttresses or ties on the walls in mid-points of the long walls may improve the seismic behavior and safety. These structural strengthening solutions, if located in the points where maximum displacements tends to develop, and if properly connected to the building structure can significantly reduce the displacement demand and damage.

\section{ACKNOWLEDGEMENTS}

The authors gratefully acknowledge the partial support by the research project 'SEISMIC-V - Vernacular Seismic Culture in Portugal' (PTDC/ATP-AQI/ 3934/2012), from the Portuguese Science and Technology Foundation (FCT).

\section{REFERENCES}

Correia, M. 2007. Rammed earth in Alentejo, Lisboa: Argumentum.

Gallego, R.; Arto I. - Mileto, Vegas, García, Soriono \& Cristini. 2015. Evaluation of seismic behavior of rammed earth structures, Earth Architecture: Past, Present and Future, London: Taylor \& Francis Group, 151-156.

Gomes, M.I.; Lopes, M.; de Brito, J. 2011. Seismic resistance of earth construction in Portugal, Engineering Structures 33(3): 932-941.

Limón, T.G.; Burego, M.A.; Gómez, A.C. 1998. Study of the materials from the factories in the tower of the Alhambra Comares, Alhambra: CEDEX.

Miccoli L.; Oliveira D.V.; Silva R.A.; Muller, U.; Schueremans, L. 2014. Static behaviour of rammed earth - experimental testing and finite element modeling, Materials and Structures DOI 10.1617/s11527-014-0411-7.

MIDAS FEA. 2014. Manual Midas FEA, London: MIDAS.

Reis, A.C., Farinha, M.B., Farinha, J.P.B. 2005. Tabelas Técnicas, Lisboa: Edições técnicas E.T.L., Lda.

Vicente, R., Rodrigues, H., Varum, H., and Mendes da Silva, J. 2011. Evaluation of Strengthening Techniques of Traditional Masonry Buildings: Case Study of a Four-Building Aggregate. J. Perform. Constr. Facil., 25(3), 202-216. 